UCRL-JC-120139

PREPRINT

CONF-950846- 53

\title{
Shock Initiation of 1,3,3-Trinitroazetidine (TNAZ)
}

\author{
R. L. Simpson \\ P. A. Urtiew \\ C. M. Tarver
}

This paper was prepared for submittal to the 1995 American Physical Society Topical Conference

Shock Compression of Condensed Matter Seattle, Washington

August 13-18, 1995

July 19, 1995

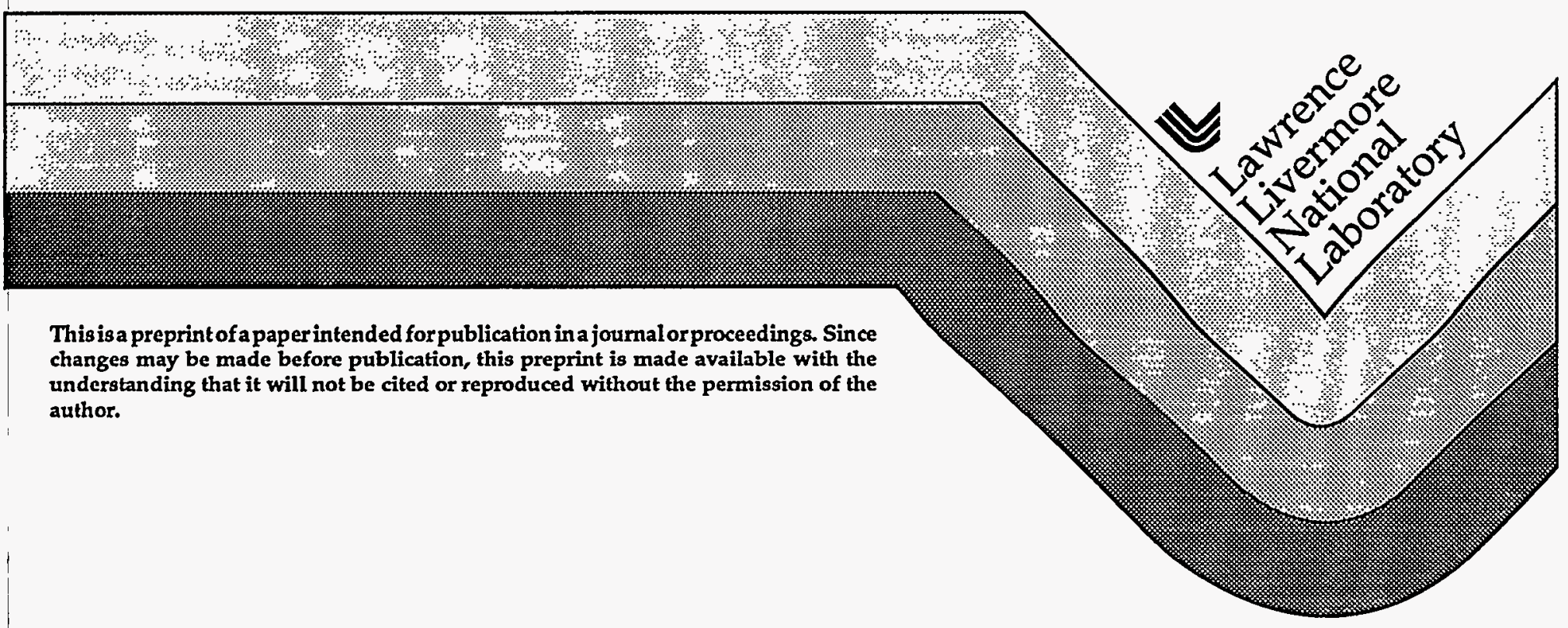




\section{DISCLAIMER}

This document was prepared as an acoount of work sponsored by an agency of the United States Government. Neither the United States Government nor the University of California nor any of their employees, makes any warranty, express or implied, or assumes any legal liability or responsibility for the accuracy, completeness, or usefulness of any information, apparatus, product, or process disclosed, or represents that its use would not infringe privately owned rights. Reference herein to any specific commercial product, process, or service by trade name, trademark, manufacturer, or otherwise, does not necessarily constitute or imply its endorsement, recommendation, or favoring by the United States Government or the University of California. The views and opinions of authors expressed herein do not necessarily state or reflect those of the United States Government or the University of California, and shall not be used for advertising or product endorsement purposes. 


\section{DISCLAIMER}

Portions of this document may be illegible in electronic image products. Images are produced from the best available original document. 


\title{
SHOCK INITIATION OF 1,3,3-TRINITROAZETIDINE (TNAZ)
}

\author{
R. L. Simpson, P. A. Urtiew and C. M. Tarver \\ Lawrence Livermore National Laboratory, \\ P.O. Box 808, L-282, Livermore, CA 94551
}

\begin{abstract}
The shock sensitivity of the pressed solid explosive 1,3,3-trinitroazetidine (TNAZ) was determined using the embedded manganin pressure gauge technique. At an initial pressure of $1.3 \mathrm{GPa}$, pressure buildup (exothermic reaction) was observed after ten $\mu \mathrm{s}$. At $2 \mathrm{GPa}$, TNAZ reacted rapidly and transitioned to detonation in approximately $13 \mathrm{~mm}$. At $3.6 \mathrm{GPa}$, detonation occurred in less than 6 $\mathrm{mm}$ of shock propagation. Thus, pure TNAZ is more shock sensitive than HMX-based eplosives but less shock sensitive than PETN-based explosives. The shocked TNAZ exhibited little reaction directly behind the shock front, followed by an extremely rapid reaction. This reaction caused both a detonation wave and a retonation wave in the partially decomposed TNAZ. An Ignition and Growth reactive model for TNAZ was developed to help understand this complex initiation phenomenon:
\end{abstract}

\section{INTRODUCTION}

The four membered ring explosive 1,3,3trinitroazetidine (TNAZ) was first synthesized by Archibald (1). This explosive is of interest because of its high energy density and its melting point of $100^{\circ} \mathrm{C}$, which means that melt casting may be possible. The small scale safety properties, calorimetric heat of detonation, and thermal explosion behavior of TNAZ were reported by Simpson et al. (2). In this paper, the shock sensitivity of TNAZ was measured at three shock pressures using embedded manganin gauge techniques (3) and calculated using the Ignition and Growth reactive flow model (4) for shock initiation and detonation in the DYNA2D hydrodynamic code (5).

\section{EXPERIMENTAL}

The experimental geometry is shown in Fig. 1. A $12.7 \mathrm{~mm}$ thick, $80 \mathrm{~mm}$ diameter aluminum flyer plate impacted a target consisting of a $6 \mathrm{~mm}$ thick, $90 \mathrm{~mm}$ diameter aluminum buffer plate and a $25 \mathrm{~mm}$ thick, $50.8 \mathrm{~mm}$ diameter TNAZ charge. The TNAZ charge was held in place by a $5 \mathrm{~mm}$ thick lexan ring. Six $0.3 \mathrm{~mm}$ thick Teflon-insulated manganin gauges were placed in pairs along the center line of the TNAZ charge at distances of 0,6 , and $12 \mathrm{~mm}$. Three experiments were fired in the $100 \mathrm{~mm}$ powder gun with aluminum flyer velocities of $0.352 \mathrm{~mm} / \mu \mathrm{s}$,
$0.483 \mathrm{~mm} / \mu \mathrm{s}$ and $0.684 \mathrm{~mm} / \mu \mathrm{s}$, producing initial shock pressures of approximately $1.3 \mathrm{GPa}, 2 \mathrm{GPa}$ and $3.6 \mathrm{GPa}$, respectively. The measured changes in resistance of the manganin gauge elements were converted to pressure histories and compared to Ignition and Growth reactive flow calculations.

\section{REACTIVE FLOW MODELING}

The Ignition and Growth reactive flow model (4) uses two Jones-Wilkins-Lee (JWL) equations of state, one for the unreacted explosive and another one

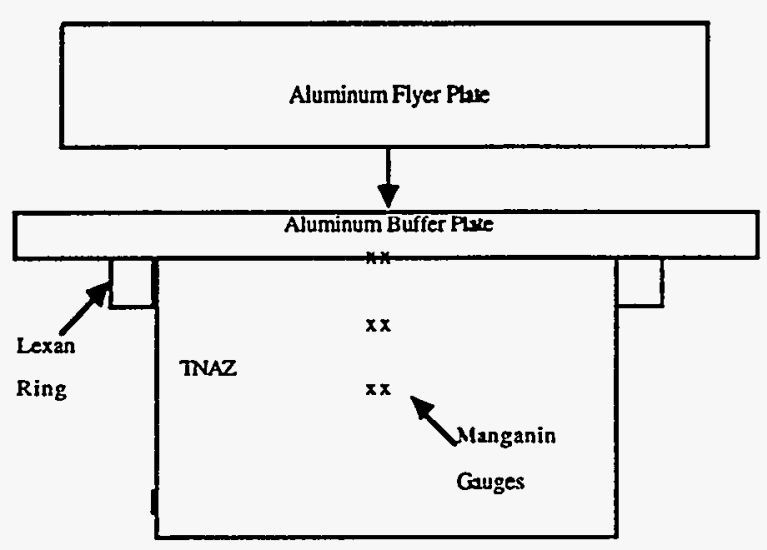

FIGURE 1. Experimental geometry for the shock initiation of TNAZ

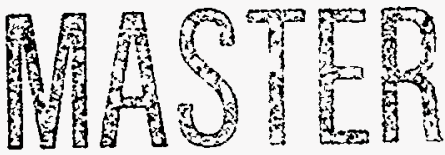


for the reaction products, in the temperature dependent form:

$$
p=A e^{-R_{1} V}+B e^{-R_{2} V}+\omega C_{v} T
$$

where $\mathrm{p}$ is pressure in Megabars, $\mathrm{V}$ is relative volume, $T$ is temperature, $\omega$ is the Gruneisen coefficient, $C_{V}$ is the average heat capacity, and $A, B$, $R_{1}$ and $R_{2}$ are constants. The equations of state are fitted to the available shock Hugoniot data. The reaction rate law is:

$$
\begin{aligned}
& d F / d t=I(1-F)^{b}\left(\rho / \rho_{o}-1-a\right)^{x}+G_{1}(1-F)^{c} F^{d} p^{y} \\
& 0<\text { F }<\text { Figmax } \quad 0<F<F G 1 \text { max } \\
& +\mathrm{G}_{2}(1-\mathrm{F})^{\mathrm{e}} \mathrm{Fg} \mathrm{p}^{\mathrm{z}} \\
& \mathrm{F}_{\mathrm{G} 2 \min }<\mathrm{F}<1
\end{aligned}
$$

where $F$ is the fraction reacted, $t$ is time, $\rho$ is the current density, $\rho_{o}$ is the initial density, $p$ is pressure in Megabars, and $I, G_{1}, G_{2}, a, b, c, d, e, g, x, y$, and $z$ are constants. As explained in previous papers (4), this three term reaction rate law models the three stages of reaction generally observed during shock initiation of heterogeneous solid explosives. The equation of state parameters for TNAZ, aluminum, and Teflon, and the Ignition and Growth rate law parameters used in the reactive flow calculations are listed in Table 1.

\section{COMPARISON OF RESULTS}

Figure 2 compares the experimental pressure histories (solid lines) with those predicted by the
Ignition and Growth model (dashed lines) for the TNAZ experiment with the intermediate aluminum flyer velocity of $0.483 \mathrm{~mm} / \mu \mathrm{s}$, which propagates a 2 GPa shock pressure into the TNAZ charge. The 0 $\mathrm{mm}$ gauges measured very little growth of reaction for the first $2 \mu s$ after impact, and then the pressure rose slowly to $5 \mathrm{GPa}$ over the next $4 \mu \mathrm{s}$. An instantaneous jump in pressure then occurred at $7 \mu \mathrm{s}$. The $6 \mathrm{~mm}$ deep gauges recorded a relatively slow pressure rise to $8 \mathrm{GPa}$ over the first $3 \mu \mathrm{s}$, followed by an instantaneous jump to over $20 \mathrm{GPa}$ at $6 \mu \mathrm{s}$. The $12 \mathrm{~mm}$ deep gauges recorded a rapid increase in pressure to over $20 \mathrm{GPa}$ just behind the shock front, indicating that the transition to detonation had nearly occurred at this distance into the TNAZ charge. The instantaneous pressure increases at the 0 and $6 \mathrm{~mm}$ gauge locations at later times than the rapid reaction at the $12 \mathrm{~mm}$ gauges indicate that the rapid transition to detonation at approximately $13 \mathrm{~mm}$ into the TNAZ charge also resulted in a rearward moving retonation wave in the partially reacted TNAZ that was recorded by the gauges at the 0 and $6 \mathrm{~mm}$ depths.

This type of very nonlinear growth of reaction has not been previously observed in our other studies of shock initiation of heterogeneous solid explosives. The other solid explosives have exhibited some degree of shock front growth as the front moves through the charge, followed by an ever increasing growth of reaction behind the shock front. Detonation occurs when the resulting pressure pulse overtakes the shock front. No retonation is observed,

\begin{tabular}{|c|c|c|c|c|c|c|c|}
\hline \multicolumn{4}{|c|}{ 1. Ignition and Growth Model Parameters for TNAZ } & \multirow{2}{*}{\multicolumn{4}{|c|}{ Reaction Rate Parameters }} \\
\hline \multirow{2}{*}{\multicolumn{4}{|c|}{$\begin{array}{l}\text { Unreacted JWL } \\
\rho_{0}=1.83 \mathrm{~g} / \mathrm{cm}^{3}\end{array}$}} & & & & \\
\hline & & & & \\
\hline \multicolumn{2}{|c|}{$\begin{array}{l}B=-0.0452515 \text { Mbar } \\
R_{1}=13.5 \\
R_{2}=1.35\end{array}$} & \multicolumn{2}{|c|}{$\begin{array}{l}\mathrm{B}=0.9057014 \mathrm{Mbar} \\
\mathrm{R}_{1}=6.00\end{array}$} & \multicolumn{2}{|l|}{$\begin{array}{l}a=0.0 \\
b=0.667\end{array}$} & \multicolumn{2}{|c|}{$\begin{array}{l}e=0.667 \\
g=0.667\end{array}$} \\
\hline \multicolumn{2}{|c|}{$\begin{array}{l}\omega=0.8695 \\
C_{V}=2.7814 \mathrm{e}-5 \mathrm{Mbar} / \mathrm{K}\end{array}$} & \multicolumn{2}{|c|}{$\begin{array}{l}\omega=0.57 \\
C_{v}=1.0 \mathrm{e}-5 \mathrm{Mbar} / \mathrm{K}\end{array}$} & \multicolumn{2}{|l|}{$\begin{array}{l}G_{1}=230 \\
y=2.0\end{array}$} & \multicolumn{2}{|c|}{$\begin{array}{l}F_{\text {igmax }}=0.02 \\
F_{G 1 \max }=0.35\end{array}$} \\
\hline \multicolumn{2}{|c|}{$\begin{array}{l}\mathrm{T}_{0}=298^{\circ} \mathrm{K} \\
\text { Shear Modulus }=0.03 \mathrm{Mbar} \\
\text { Yield Strength=0.001 Mbar } \\
\text { 2. Gruneisen Parameters for In }\end{array}$} & \multicolumn{2}{|c|}{$\mathrm{E}_{0}=0.100 \mathrm{Mbar}$} & \multicolumn{2}{|l|}{$\begin{array}{l}c=0.667 \\
d=0.333\end{array}$} & \multicolumn{2}{|c|}{$F_{G 2 \min }=0.35$} \\
\hline & \multicolumn{7}{|c|}{$\begin{array}{c}p=\rho_{o} c^{2} \mu\left[1+\left(1-\gamma_{0} / 2\right) \mu-a / 2 \mu^{2}\right] /\left[1-\left(S_{1}-1\right) \mu-S_{2} \mu^{2} /(\mu+1)-S_{3} \mu^{3} /(\mu+1)^{2}\right]^{2}+\left(\gamma_{o}+a \mu\right) E \\
\text { where } \mu=\rho / \rho_{0}-1 \text { and } E \text { is thermal energy }\end{array}$} \\
\hline Inert & $\rho_{0}\left(\mathrm{~g} / \mathrm{cm}^{3}\right)$ & $\mathrm{c}(\mathrm{mm} / \mathrm{ms})$ & $s_{1}$ & $S_{2}$ & $S_{3}$ & $\gamma_{0}$ & a \\
\hline 6061-T6 Al & 2.703 & 5.24 & 1.4 & 0.0 & 0.0 & 1.97 & 0.48 \\
\hline Lexan & 1.193 & 1.933 & 2.04 & 0.0 & 0.0 & 0.61 & 0.0 \\
\hline Teflon & 2.15 & 1.68 & 1.123 & 3.98 & -5.8 & 0.59 & 0.0 \\
\hline
\end{tabular}
because the explosive has been entirely reacted during the buildup process. Homogeneous liquid explosives and void free solid explosives exhibit a different

TABLE 1. Equation of State and Reaction Rate Parameters 


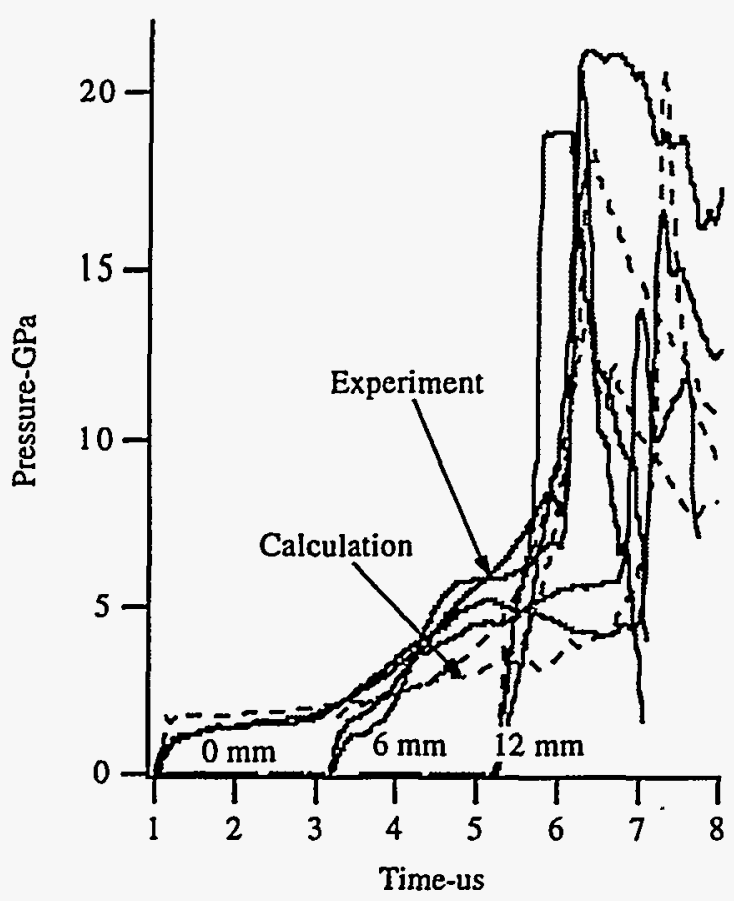

FIGURE 2. Pressure histories for TNAZ impacted at $0.483 \mathrm{~mm} / \mu \mathrm{s}$ by an aluminum flyer plate

shock initiation pattern, in which a rapid reaction is initiated at or near the rear boundary of the explosive charge after a time delay proportional to the initial shock pressure. This rapid reaction creates a "super." detonation wave in the precompressed material, which then overtakes the initial shock front and decays to a Chapman-Jouguet (CJ) detonation. Thus the TNAZ initiation pattern in Fig. 2 appears to be a combination of the two limiting cases.

To account for this initiation process, the Ignition and Growth reactive flow model for TNAZ ignites less than $2 \%$ of the TNAZ near the shock front in the first rate of Eq. (2), allows a relatively slow growth of reaction to $35 \%$ reacted using the second rate in Eq. (2), and then causes a very rapid reaction to consume the remainder of the explosive using the third rate in Eq. (2). The calculated pressure histories agree well with the manganin records in Fig. 2, particularly with regard to the pressures and times of the transition to detonation and the arrival of the retonation wave at the 0 and 6 mm depths. The measured and calculated retonation velocity between the 0 and $6 \mathrm{~mm}$ gauges is approximately $7.4 \mathrm{~mm} / \mu \mathrm{s}$, and the peak pressure of this retonation wave decreases as it travels through TNAZ that has had longer to react.

The other two experiments measure the relatively slow growth of reaction behind the shock front and the rapid transition to detonation at high pressure. Figure 3 contains the experimental and calculated pressure histories for the lowest impact velocity experiment, $0.352 \mathrm{~mm} / \mu \mathrm{s}$, which yields an initial shock pressure of $1.3 \mathrm{GPa}$. After a delay of 5 $\mu \mathrm{s}$, the pressure grows slowly over the next $5-6 \mu \mathrm{s}$, reaching $5-8 \mathrm{GPa}$, as in Fig. 3. The pressures then increase rapidly near the end of the records at $13-14$ $\mu \mathrm{s}$, which is close to the time limit for the onedimensional flow after which side rarefactions cause gauge problems. The Ignition and Growth pressure histories also reach $5-8 \mathrm{GPa}$, corresponding to $35 \%$ reaction for these TNAZ equations of state. The calculation predicts a transition to detonation near the end of the $25 \mathrm{~mm}$ thick TNAZ charge, and the resulting retonation wave then reaches the gauge positions at $12-14 \mu \mathrm{s}$. Two-dimensional calculations of this experiment predict that the gauges are still in the one-dimensional flow region in this time frame, but the sound velocity in such a rapidly reacting mixture is unknown. So it is impossible to prove that the experimental pressure increases at late times in Fig. 3 are the arrival of the retonation wave. However, the earlier portions of the gauge records and calculations do illustrate the slow growth part of the TNAZ reactive flow at $1.3 \mathrm{GPa}$. To account the large differences in TNAZ reactivity with respect to the initial shock pressure, the growth rate has a $\mathrm{p}^{2}$ dependence in Eq. (2) and therefore

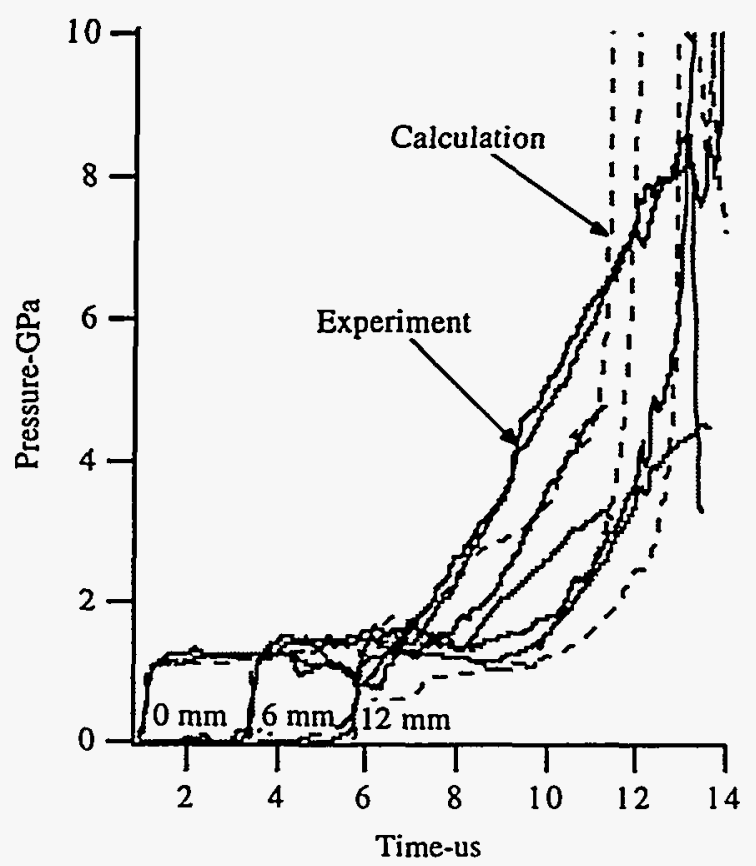

FIGURE 3. Pressure histories for TNAZ impacted at $0.352 \mathrm{~mm} / \mu \mathrm{s}$ by an aluminum flyer plate 
decreases sharply when the rarefaction wave from the rear of the aluminum flyer plate reaches the gauge location. This results in lower pressures than the gauge records in the $7-12 \mu$ s time frame of Fig. 3.

The experimental and calculated results for the highest aluminum flyer velocity experiment, 0.684 $\mathrm{mm} / \mu \mathrm{s}$, producing a $3.6 \mathrm{GPa}$ shock in TNAZ, are shown in Fig. 4. After $0.6 \mu \mathrm{s}$, the $0 \mathrm{~mm}$ gauges record a rapid growth reaction to $14 \mathrm{GPa}$. The 6 and $12 \mathrm{~mm}$ gauges record high pressures characteristic of a detonation wave with a velocity of $8.24 \mathrm{~mm} / \mu \mathrm{s}$ between gauge packages. Since the steady state CJ detonation velocity of TNAZ is $8.7 \mathrm{~mm} / \mu \mathrm{s}$, the buildup process is not complete at the $6 \mathrm{~mm}$ gauges, as evidenced by the lower peak pressures and the excess transit times to the $12 \mathrm{~mm}$ gauges. The Ignition and Growth calculations predict detonation before the $6 \mathrm{~mm}$ gauge, at approximately $3 \mathrm{~mm}$, and a peak pressure of $14 \mathrm{GPa}$ at the $0 \mathrm{~mm}$ gauge. However, in spite of the extreme dependence of the growth reaction rate on pressure, the $0 \mathrm{~mm}$ calculation underestimates the initial portion of the pressure rise. The calculations predict no retonation wave back to the $0 \mathrm{~mm}$ gauge, because the TNAZ has completely reacted. No evidence of a retonation wave at $0 \mathrm{~mm}$ is observed experimentally. Thus, at $3.6 \mathrm{GPa}, \mathrm{TNAZ}$ appears to pass through the slow growth process very rapidly and detonate promptly.

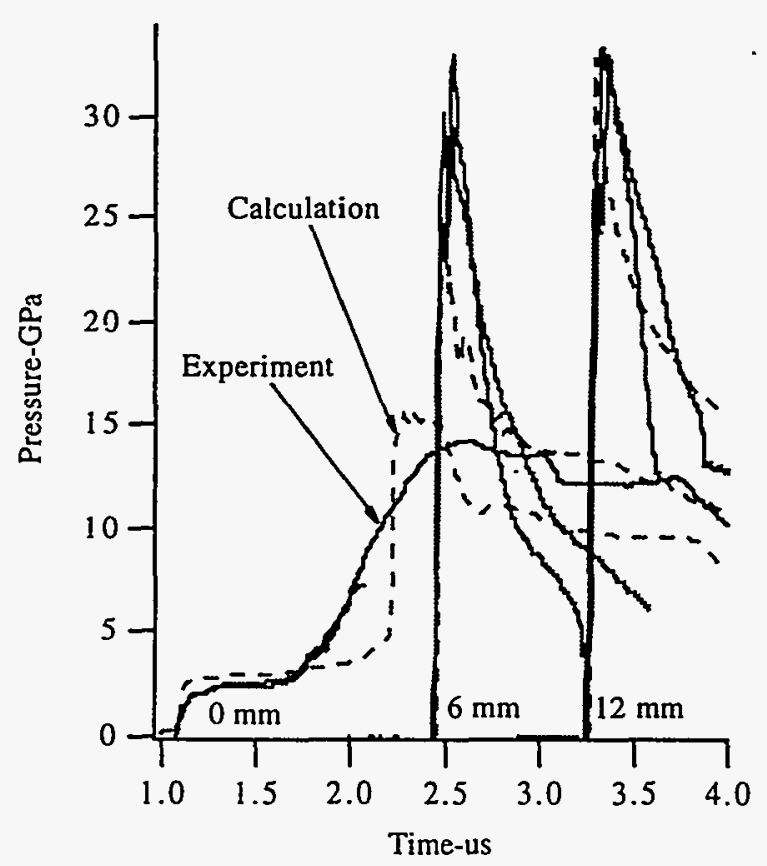

FIGURE 4. Pressure histories for TNAZ impacted at $0.684 \mathrm{~mm} / \mu$ s by an aluminum flyer plate

\section{SUMMARY}

The shock sensitivity of TNAZ has been determined using embedded manganin pressure gauges and the Ignition and Growth reactive flow model. A complex initiation mechanism has been postulated to explain the relatively slow growth of reaction behind the shock front followed by a rapid transition to detonation, which also produces a retonation wave in the partially reacted TNAZ. Such a retonation wave has not been previously observed in the heterogeneous solid explosives we have studied. This process may be related to time-dependent melting of TNAZ during shock compression, causing it to behave in a more homogeneous manner. Additional shock initiation experiments at various initial densities and initial temperatures are required to better understand the shock initiation of TNAZ.

The molecular formula of TNAZ is $\mathrm{C}_{3} \mathrm{H}_{4} \mathrm{~N}_{4} \mathrm{O}_{6}$, which results in an oxygen balanee greater than HMX and less than PETN. This papper shows that TNAZ is also intermediate between HMX and PETN in terms of its shock sensitivity.

\section{ACKNOWLEDGEMENTS}

The TNAZ was kindly provided by Dr. Gary Parsons of Eglin Air Force Base. The authors would also like to thank Frank Garcia for firing the four inch gun shots and Leona Meegan for assembling the embedded gauge targets. This work was performed under the auspices of the U.S. Dept. of Energy by Lawrence Livermore National Laboratory under contract No. W-7405-ENG-48.

\section{REFERENCES}

1. Archibald, T. G., Organic Chemistry 55, 2920-2924 (1990).

2. Simpson, R. L., Garza, R. G., Foltz, M. F., Ornellas, D. L., and Urtiew P. A., "Characterization of "TNAZ," Lawrence Livermore National Laboratory Report UCRL-JC-ID-119672, December 1994.

3. Urtiew, P. A., Erickson, L. M., Hayes, B., and Parker, N. L., Combustion, Explosion and Shock Waves 22, 597-614 (1986).

4. Tarver, C. M., Hallquist, J. O., and Erickson, L. M., in Eighth Symposium (International) on Detonation, Naval Surface Weapons Center NSWC 86-194, Albuquerque, NM, 1985, pp. 951-961.

5.. Whirley, R. G., Engelmann, B. E., and Hallquist, J. O., "DYNA2D User Manual," Lawrence Livermore National Laboratory Report UCRL-MA-110630, April 1992. 